\title{
PLASMA CITRULLINE LEVELS IN PRETERM NEONATES WITH NECROTIZING ENTEROCOLITIS
}

\author{
H. Ioannou ${ }^{1}$, E. Diamanti ${ }^{2}$, Z. Tsampoura ${ }^{2}$, V. Drossou-Agakidou ${ }^{2}$, P. Avgoustides-Savvopoulou ${ }^{1}$ \\ ${ }^{1} 1$ st Dept of Pediatrics, ${ }^{2} 1$ st Dept of Neonatology and Neonatal Intensive Care, Aristotle University of \\ Thessaloniki,Hippokration Hospital, Thessaloniki, Greece
}

Background and aim: As circulating citrulline is derived almost exclusively from the small intestine, its plasma levels have been proposed as a reliable marker of intestinal function. The aim of this study was to assess longitudinal changes of plasma citrulline in preterm neonates with necrotizing enterocolitis (NEC) and correlate them with the course of the disease.

Methods: Plasma citrulline levels were measured prospectively in 23 preterm neonates with NEC (6 with stage I and 17 with stage II) during the course of the disease. Serial citrulline determinations in 24 healthy preterm neonates on $2,7,14,21$, and 28 days of life (DOL), served as reference values.

Results: In healthy preterm neonates plasma citrulline progressively increased with age. In neonates with NEC, mean citrulline levels were significantly lower than the respective control values (DOL 7: $16.9 \pm 4.3$ vs $20.5 \pm 4.5 \mu \mathrm{mol} / \mathrm{L}, \mathrm{p}<0.05$; DOL $14: 18 \pm 4.2$ vs $23.5 \pm 4.3 \mu \mathrm{mol} / \mathrm{L}, \mathrm{p}<0.01 ;$ DOL $21: 17 \pm 2.5$ vs $30 \pm 5.7$ $\mu \mathrm{mol} / \mathrm{L}, \mathrm{p}<0.01)$. Further analysis according to the NEC stage showed that neonates with stage II NEC had significantly lower values than neonates with stage I ( $16 \pm 3.3$ vs $19 \pm 3.4 \mu \mathrm{mol} / \mathrm{L}, \mathrm{p}<0.05)$. Consecutive citrulline determinations revealed that plasma levels increased during reintroduction and progression of enteral nutrition.

Conclusions: Our findings provide preliminary evidence that citrulline levels are reduced in preterm neonates with NEC compared to age-matched controls. Serial citrulline determinations could be helpful in monitoring improvement of intestinal function during the course of NEC. 